\title{
Oxidation Behavior of Rare-Earth-Containing Pb-Free Solders
}

\author{
M.A. DUDEK ${ }^{1}$ and N. CHAWLA ${ }^{1,2}$ \\ 1.-School of Materials, Ira A. Fulton School of Engineering, Arizona State University, Tempe, \\ AZ 85287-8706, USA. 2.-e-mail: nchawla@asu.edu
}

\begin{abstract}
We have previously shown that small additions of the rare-earth (RE) element La to Sn-Ag-Cu alloys significantly increases their ductility, without significant loss in the overall strength. However, due to the high reactivity of La with oxygen, oxidation of the La-containing phases can affect the mechanical performance of the solder. In this work, we have investigated the effect of the addition of 2 wt.\% Ce, La and $\mathrm{Y}$ on the oxidation behavior of $\mathrm{Sn}-3.9 \mathrm{Ag}-0.7 \mathrm{Cu}$. Oxidation kinetics were established by heating samples in ambient air to $60^{\circ} \mathrm{C}, 95^{\circ} \mathrm{C}$ or $130^{\circ} \mathrm{C}$ for up to $250 \mathrm{~h}$. Microstructural characterization of the samples, before and after oxidation, was conducted in order to determine the influence of RE-containing phases on the oxidation kinetics. The oxidation mechanism, including the phenomenon of Sn whiskering during oxidation, is also discussed.
\end{abstract}

Key words: Rare-earth, Pb-free solder, oxidation

\section{INTRODUCTION}

In recent years there has been a growing interest in $\mathrm{Pb}$-free solder alloys doped with small amounts of rare-earth (RE) elements due to enhanced physical and mechanical properties relative to conventional $\mathrm{Pb}$-free alloys. ${ }^{1-17}$ Several authors have shown that the addition of small amounts of RE elements can decrease alloy melting temperature, ${ }^{2,8,14}$ improve wettability, ${ }^{2,5,9,16}$ and even promote strong bonding to semiconductors such as silicon. ${ }^{1,13}$ Rare earths have also been shown to refine the solder microstructure by decreasing the Sn grain size, ${ }^{2,9,10,17}$ and intermetallic particle size,,${ }^{2,9,15,17}$ and decrease the $\mathrm{Cu}_{6} \mathrm{Sn}_{5}$ layer that forms between the $\mathrm{Cu}$ substrate and the $\mathrm{Pb}$-free solder. ${ }^{14,15}$ The mechanical response of these materials is dependent on the type of $\mathrm{RE}$ elements, and their concentration and morphology. RE additions have been shown to increase the strength of $\mathrm{Sn}-\mathrm{Ag}^{2,5}$ and $\mathrm{Sn}-\mathrm{Ag}-\mathrm{Cu}$ alloys, ${ }^{8,9,15,16}$ increase strain-to-failure in $\mathrm{Sn}-\mathrm{Ag}^{5}$ and $\mathrm{Sn}-\mathrm{Ag}-\mathrm{Cu}$ alloys, ${ }^{9}$ and improve creep resistance in $\mathrm{Sn}-\mathrm{Ag}^{2}$ and Sn-Ag-Cu alloys. ${ }^{7,16}$

(Received May 1, 2008; accepted August 14, 2008;

published online September 16, 2008)
In previous work, ${ }^{11,12}$ we reported that small $\mathrm{La}$ additions (0.1 wt.\% and 0.5 wt.\%) to $\mathrm{Sn}-\mathrm{Ag}-\mathrm{Cu}$ resulted in a significant increase in ductility compared with $\mathrm{Sn}-\mathrm{Ag}-\mathrm{Cu} / \mathrm{Cu}$ joints. At these small $\mathrm{La}$ concentrations, a homogenously distributed $\mathrm{LaSn}_{3}$ intermetallic phase forms in the solder. We have shown that the $\mathrm{LaSn}_{3}$ particles are directly responsible for the higher ductility observed in these materials, by allowing microscopic voids to nucleate throughout the solder volume (instead of localized strain at the solder-intermetallic interface), and homogenizing the strain in the solder joint.

Due to the reactive nature of $\mathrm{RE}$ elements with oxygen, some of these solder systems are prone to severe oxidation even under ambient conditions. In the case of La-containing solders, oxidation leads to degradation in the mechanical performance as well as poor reflow quality. ${ }^{18}$ Chuang and co-authors ${ }^{19-22}$ have shown that a significant amount of $\mathrm{Sn}$ whiskering takes place on the surfaces of $\mathrm{Pb}$-free solders containing $\mathrm{Ce}$, La, and Lu. Similar observations have been made by Jiang and Xian ${ }^{23}$ with solders containing $\mathrm{Nd}$. It appears that the RE-rich intermetallic phases that form in these solders are highly reactive with oxygen, leading to a complex oxidation process that produces Sn whiskers. The 
tendency of RE-containing phases to oxidize in other material systems has also been documented. Niu and co-authors ${ }^{24-26}$ have shown that RE-containing intermetallics in $\mathrm{Fe}, \mathrm{Co}$, and $\mathrm{Ag}$ systems are susceptible to oxidation. Anzel ${ }^{27}$ observed the oxidation of $\mathrm{Cu}-\mathrm{Er}$ and $\mathrm{Cu}-\mathrm{Yb}$ phases in $\mathrm{Cu}$ alloys. The tendency of RE-containing solders to oxidize has only recently been established. Much work remains to be done in order to understand the underlying mechanisms responsible for this oxidation behavior.

In this study, the oxidation behavior of Sn-3.9Ag0.7Cu-2La, Sn-3.9Ag-0.7Cu-2Ce and Sn-3.9Ag$0.7 \mathrm{Cu}-2 \mathrm{Y}$ was investigated at $60^{\circ} \mathrm{C}, 95^{\circ} \mathrm{C}$, and $130^{\circ} \mathrm{C}$. The microstructure evolution and kinetics of oxidation were studied. It will be shown that all materials exhibited parabolic oxidation rates, although the Ce-containing solder had the best oxidation resistance. The relationship between microstructure and mechanisms for oxidation in these materials is discussed in detail.

\section{MATERIALS AND EXPERIMENTAL PROCEDURES}

Vacuum-melted ingots of Sn-Ag-Cu with 2 wt.\% $\mathrm{La}, \mathrm{Ce}$ or $\mathrm{Y}$ were prepared. High-purity Sn-3.9Ag$0.7 \mathrm{Cu}$ ingots (Indium, Ithica, NY) were cut into small rectangular pieces $(6.5 \mathrm{~mm} \times 6.5 \mathrm{~mm} \times$ $13 \mathrm{~mm}$ ) and mixed with La, Ce or Y shot, roughly $2 \mathrm{~mm}^{3}$ to $8 \mathrm{~mm}^{3}$ in size (ESPI, Ashland, OR, 99.995\% pure, packed under argon). Due to their reactive nature with oxygen, the $\mathrm{RE}$ elements and solder were mixed in a helium glove box with a partial pressure of $\mathrm{O}_{2}$ of less than $20 \mathrm{ppm}$. Inside the glove box, the RE elements and solder alloy were mixed in a quartz ampoule (12 $\mathrm{mm}$ in diameter). With a closed stopcock, the quartz ampoule was taken out of the glove box, evacuated to $10^{-5}$ Torr and hermetically sealed with a blow torch. The sealed ampoules were heated to $1000^{\circ} \mathrm{C}$ for $4 \mathrm{~h}$, and periodically mixed by rotating the ampoule, in order to homogenize the liquid metal. The ampoules were then water quenched, removed from the ampoule, and sectioned.

Microstructural characterization was conducted on the as-processed ingot material. Ingots were sectioned and polished to a final finish of $0.05 \mu \mathrm{m}$ colloidal silica. Optical microscopy, scanning electron microscopy (SEM), and quantitative image analysis (ImageJ, Gaithersburg, MD) were conducted to quantify the size and spacing of RE-containing intermetallic phases. The intermetallic phases of interest were fit to ellipses to estimate their size and aspect ratio. Interparticle spacing was calculated using a finite-body tessellation method. In this method, a near-neighbor distance is defined as the shortest distance between two particles that share a cell wall in the tessellated image. ${ }^{28}$ Energydispersive spectroscopy (EDS) analysis and x-ray diffraction (XRD) were also used to confirm the composition of the RE-containing intermetallics.
XRD characterization was conducted (Panalytical XPert Pro MRD) with a real-time multiple strip (RTMS) Xcelerator detector, using $\mathrm{CuK}$ radiation. The specimens were scanned from a $2 \theta$ of $20 \mathrm{deg}$ to $90 \mathrm{deg}$ with a step increment and total time of $0.025 \mathrm{deg} / \mathrm{s}$ and $45 \mathrm{~min}$, respectively.

The oxidation behavior of $\mathrm{Sn}-3.9 \mathrm{Ag}-0.7 \mathrm{Cu}-2 \mathrm{La}$, $\mathrm{Sn}-3.9 \mathrm{Ag}-0.7 \mathrm{Cu}-2 \mathrm{Ce}$, and $\mathrm{Sn}-3.9 \mathrm{Ag}-0.7 \mathrm{Cu}-2 \mathrm{Y}$ was studied at $60^{\circ} \mathrm{C}, 95^{\circ} \mathrm{C}$, and $130^{\circ} \mathrm{C}$. Oxidation of the materials was characterized by measuring the weight change at various time intervals at constant temperatures. Ingots of each material were sectioned into small disks approximately $0.5 \mathrm{~mm}$ thick. The disks were polished to a 2000 grit finish, ultrasonically cleaned, fixed in a preoxidized aluminum mount, and weighed. The weight was measured on an analytical balance with a resolution of $\pm 0.2 \mathrm{mg}$. After the initial weight measurement, samples were placed into a preheated furnace. At certain time intervals, the samples were taken out of the furnace, allowed to cool, and then weighed. Weighing at each interval was repeated three times to ensure accuracy of the measurement. The samples were then placed back in the hot furnace for a given time period and the process was repeated for up to $250 \mathrm{~h}$. These samples were also prepared for microstructural characterization. The disks were polished to a $0.05 \mu \mathrm{m}$ colloidal finish and placed into the furnace, followed by SEM analysis. Samples oxidized for $100 \mathrm{~h}$ were also cross-sectioned and polished to analyze the depth of oxide penetration. XRD was conducted on the surfaces of sample disks oxidized at $95^{\circ} \mathrm{C}$ for $250 \mathrm{~h}$ to determine the composition and phase of the oxidation products.

A focused ion beam (FIB) was used to crosssection oxidized samples of $\mathrm{Sn}-3.9 \mathrm{Ag}-0.7 \mathrm{Cu}-2 \mathrm{La}$ to study Sn whiskers formed during oxidation. Samples were first coated with a $1-\mu \mathrm{m}$-thick Pt layer using the ion beam to protect from subsequent beam damage. A trench was milled using the ion beam at $30 \mathrm{kV}$ and a current of $5 \mathrm{nA}$. The initial cleaning cross-section was performed at $30 \mathrm{kV}$ and $0.3 \mathrm{nA}$, with subsequent cleaning sections using smaller currents to a final ion beam current of $30 \mathrm{pA}$. Samples were imaged with both secondary electron $(5 \mathrm{kV}, 98 \mathrm{pA})$ and ion beam $(30 \mathrm{kV}, 10 \mathrm{pA})$ modes.

\section{RESULTS AND DISCUSSION}

\section{As-Processed Microstructural Characterization}

Representative microstructures of as-processed Sn-3.9Ag-0.7Cu-2La, Sn-3.9Ag-0.7Cu-2Ce, and $\mathrm{Sn}-3.9 \mathrm{Ag}-0.7 \mathrm{Cu}-2 \mathrm{Y}$ are shown in Fig. 1. All microstructures consisted of Sn-dendrites and a eutectic mixture of $\mathrm{Ag}_{3} \mathrm{Sn}$ and $\mathrm{Cu}_{6} \mathrm{Sn}_{5}$ intermetallics distributed in the Sn-rich matrix. The resulting RE-containing phases (dark phases in the micrographs) consisted of homogeneously distributed $\mathrm{LaSn}_{3}, \mathrm{CeSn}_{3}$ and $\mathrm{YSn}_{3}$ particles, respectively (Fig. 2). The RE phases were considerably larger in 

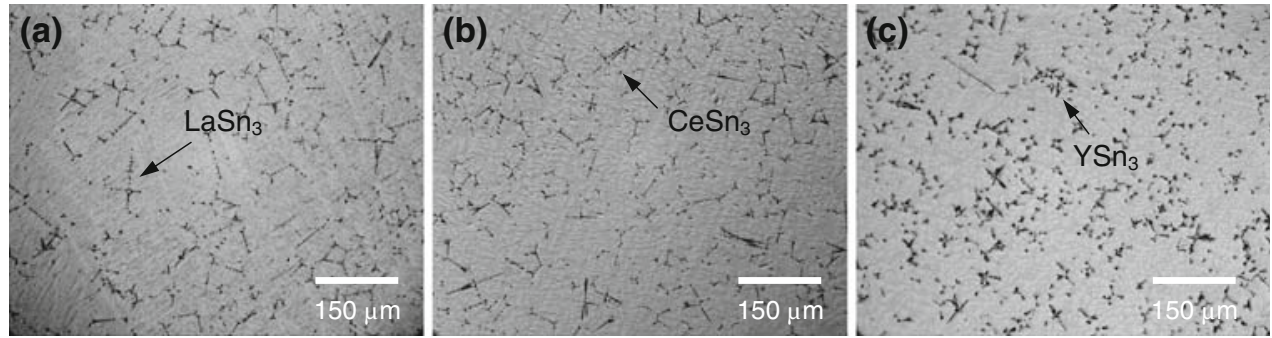

Fig. 1. As-processed optical images of (a) Sn-3.9Ag-0.7Cu-2La, (b) Sn-3.9Ag-0.7Cu-2Ce, and (c) Sn-3.9Ag-0.7Cu-2Y. Dark phases represent the RE-containing intermetallics.
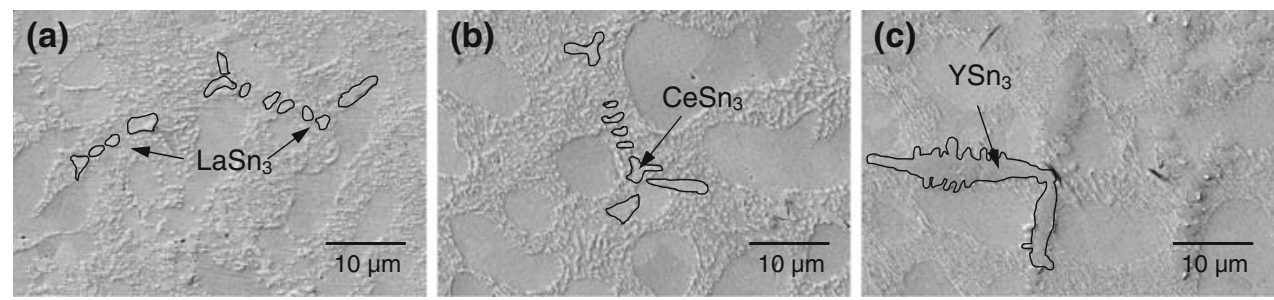

Fig. 2. High-magnification SEM images of (a) $\mathrm{LaSn}_{3}$ in Sn-3.9Ag-0.7Cu-2La, (b) $\mathrm{CeSn}_{3}$ in Sn-3.9Ag-0.7Cu-2Ce, and (c) YSn ${ }_{3}$ in Sn-3.9Ag$0.7 \mathrm{Cu}-2 \mathrm{Y}$. Some RE intermetallics are outlined in black.

size than the other intermetallic phases, i.e., $\mathrm{Ag}_{3} \mathrm{Sn}$ and $\mathrm{Cu}_{6} \mathrm{Sn}_{5}$, and surrounded the boundaries of the Sn dendrites. Recent analysis by Dudek and Chawla $^{29}$ on furnace-cooled Sn-Ag-Cu-La alloys, using three-dimensional visualization techniques, showed that the $\mathrm{LaSn}_{3}$ intermetallics are actually complex dendrites, with small amounts of entrapped Sn within each dendrite.

XRD analysis of the alloys was conducted in order to confirm the composition of the particles. XRD patterns were compared to $\mathrm{Sn}-3.9 \mathrm{Ag}-0.7 \mathrm{Cu}$ to help distinguish the peaks related to the $\mathrm{RE}$ intermetallics (Fig. 3). Peaks for pure $\mathrm{Sn}, \mathrm{Ag}_{3} \mathrm{Sn}$, and $\mathrm{Cu}_{6} \mathrm{Sn}_{5}$ phases are labeled in Fig. 3. XRD patterns for the RE-containing solders possessed one additional lowintensity peak (dotted lines in Fig. 3) which can be attributed to the RE intermetallics. For the La- and Ce-containing solders, the position of this XRD peak matched cubic $\mathrm{LaSn}_{3}$ and $\mathrm{CeSn}_{3}$, respectively. Although no established reference was found for $\mathrm{YSn}_{3}$ at ambient temperature, its diffraction pattern has been simulated using crystallographic data from Palenzona and Manfrinetti ${ }^{30}$ and Skolozdra et al. ${ }^{31} \mathrm{YSn}_{3}$ in its low-temperature ambient-pressure form is thought to be nonstoichiometric, with its structure more closely resembling $\mathrm{YSn}_{2.75}$. The major diffraction peak (113) is expected at $31.4 \mathrm{deg}$, but was not found. The only unidentified peak at $33.6 \mathrm{deg}$, which exists in the Sn-3.9Ag-0.7Cu-2Y pattern, is most probably a Y-Sn intermetallic; however, no known Y-Sn intermetallics matched this diffraction peak. It is possible that the crystallographic data provided by Palenzona and Manfrinetti needs to be re-examined, or that the crystal structure present in this material is of a different form. Nonetheless, EDS results indicate that a 3:1 ratio exists between $\mathrm{Y}$ and $\mathrm{Sn}$ in the intermetallic. The Y-Sn phase diagram also predicts the formation of this phase. ${ }^{32}$ Thus $\mathrm{YSn}_{3}$ is likely present in this alloy, although the crystal structure could not be determined from the present XRD analysis.

From Fig. 1 it appears that the size, distribution, and morphology of $\mathrm{LaSn}_{3}, \mathrm{CeSn}_{3}$, and $\mathrm{YSn}_{3}$ are fairly similar. Briefly, micrographs were segmented into black-and-white images. Image analysis software (ImageJ, Gaithersburg, MD) was employed to approximate the particles to ellipses. The ratio of the major to minor axis of the ellipse was used to calculate the aspect ratio of the particle. The quantitative analysis is shown in Table I, which includes volume fraction, size, spacing, and aspect ratio for the $\mathrm{RE}$ intermetallics present in $\mathrm{Sn}-3.9 \mathrm{Ag}-0.7 \mathrm{Cu}-2 \mathrm{La}, \mathrm{Sn}-3.9 \mathrm{Ag}-0.7 \mathrm{Cu}-2 \mathrm{Ce}$, and Sn-3.9Ag-0.7Cu-2Y. The volume fraction of the intermetallics is around $8 \%$ to $9 \%$. The particles have an aspect ratio of about 2 and range in size from $3 \mu \mathrm{m}$ to $6 \mu \mathrm{m}$.

\section{Oxidation Kinetics}

Figure 4 shows weight change versus time for Sn-3.9Ag-0.7Cu-2La, Sn-3.9Ag-0.7Cu-2Ce, and Sn-3.9Ag-0.7Cu-2Y at $60^{\circ} \mathrm{C}, 95^{\circ} \mathrm{C}$, and $130^{\circ} \mathrm{C}$. The data was normalized by the surface area of the samples. The rate of oxidation increases with temperature for all the materials studied. The La- and Y-containing solders behave similarly, with similar oxidation curves at each temperature. $\mathrm{Sn}-3.9 \mathrm{Ag}-0.7 \mathrm{Cu}-2 \mathrm{Ce}$, however, has significantly 

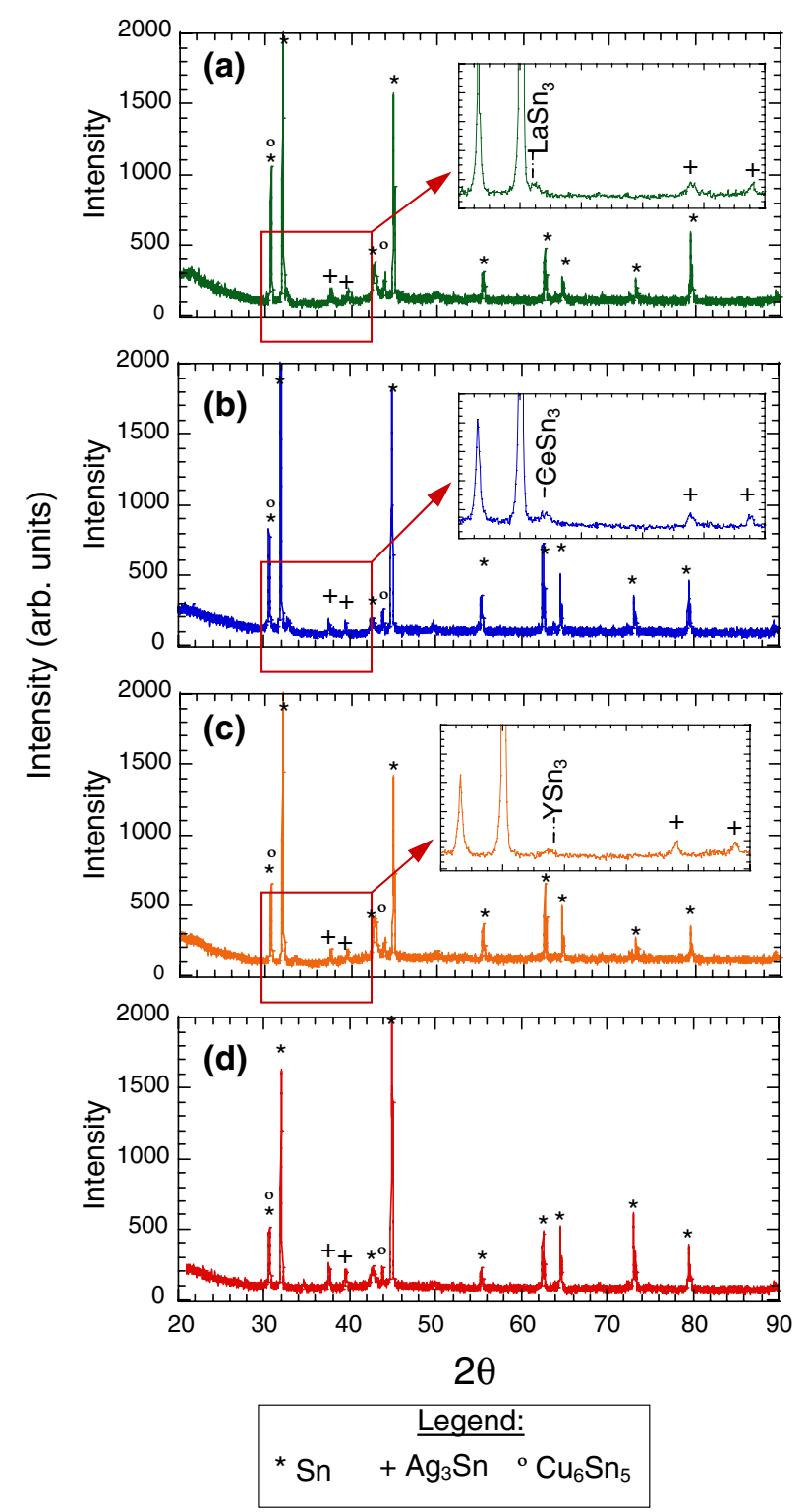

Fig. 3. XRD scans for as-processed (unoxidized): (a) Sn-3.9Ag0.7Cu-2La, (b) Sn-3.9Ag-0.7Cu-2Ce, and (c) Sn-3.9Ag-0.7Cu-2Y. Sn-3.9Ag-0.7Cu (d) was also scanned to aid in peak identification.

Table I. Summary of Microstructural Characterization for As-Processed Solder Alloys

\begin{tabular}{|c|c|c|c|}
\hline & \multicolumn{3}{|c|}{ Sn-3.9Ag-0.7Cu } \\
\hline & 2La & $2 \mathrm{Ce}$ & $2 \mathbf{Y}$ \\
\hline \multicolumn{4}{|l|}{$\begin{array}{l}\text { Intermetallic } \\
\text { characteristics }\end{array}$} \\
\hline Volume fraction (\%) & $9.1 \pm 0.2$ & $8.6 \pm 0.4$ & $8.9 \pm 0.3$ \\
\hline Major axis $(\mu \mathrm{m})$ & $5.6 \pm 1.0$ & $6.1 \pm 1.2$ & $5.4 \pm 0.8$ \\
\hline Minor axis $(\mu \mathrm{m})$ & $2.3 \pm 0.6$ & $3.2 \pm 0.8$ & $2.8 \pm 0.7$ \\
\hline Aspect ratio & $2.3 \pm 0.5$ & $1.9 \pm 0.3$ & $2.0 \pm 0.6$ \\
\hline $\begin{array}{l}\text { Interparticle } \\
\quad \text { spacing }(\mu \mathrm{m})\end{array}$ & $9.6 \pm 1.0$ & $10.1 \pm 0.7$ & $11.2 \pm 0.9$ \\
\hline
\end{tabular}

better oxidation resistance. The oxidation process for all alloys in the temperature range studied obeys a parabolic rate law, as shown by the linear relationship in the plots of normalized weight change versus time $^{1 / 2}$ (Fig. 5). This suggests a diffusioncontrolled process. Parabolic oxidation may be described by the equation ${ }^{33}$ :

$$
\frac{\mathrm{d} \xi}{\mathrm{d} t}=\frac{k^{\prime}}{\xi},
$$

where $\xi$ is the thickness of the oxide scale, $k^{\prime}$ is the rate constant, and $t$ is the oxidation time. This equation can be modified for parabolic weight increase according to ${ }^{33}$ :

$$
\left(\frac{\Delta W}{A}\right)^{2}=k_{\mathrm{p}} t
$$

where $\Delta W$ is the mass change of the sample, $A$ is the sample surface area, $k_{\mathrm{p}}$ is the parabolic rate constant, and $t$ is the time in the oxidizing environment. The values of $k_{\mathrm{p}}$ computed from the kinetic data in Fig. 4 are given in Table II. Notice that the oxidation rate for $\mathrm{Sn}-3.9 \mathrm{Ag}-0.7 \mathrm{Cu}-2 \mathrm{Ce}$ is an order of magnitude smaller than those for $\mathrm{Sn}-3.9 \mathrm{Ag}-0.7 \mathrm{Cu}-$ $2 \mathrm{La}$ and $\mathrm{Sn}-3.9 \mathrm{Ag}-0.7 \mathrm{Cu}-2 \mathrm{Y}$ in the temperature range studied. The activation energy for oxidation was calculated from the Arrhenius equation relating the temperature dependence of the oxidation rate constants ${ }^{34}$ :

$$
k_{\mathrm{p}}=A \mathrm{e}^{\frac{-Q}{R T}}
$$

where $Q$ is the activation energy for oxidation and $T$ is absolute temperature. Values for activation energies are given in Table III. For the temperature range studied, the activation energies for the alloys are very similar. This signifies that the oxidation mechanism for the materials is likely the same. A more detailed discussion of the precise mechanisms for oxidation are presented in the next section.

\section{Microstructure Evolution During Oxidation}

Based on SEM and EDS data, oxidation of Sn-3.9Ag-0.7-2La, Sn-3.9Ag-0.7-2Ce, and Sn-3.9Ag$0.7-2 \mathrm{Y}$ alloys is almost entirely controlled by the oxidation of the $\mathrm{LaSn}_{3}, \mathrm{CeSn}_{3}$, and $\mathrm{YSn}_{3}$ intermetallics, respectively. The oxide covers the intermetallic surfaces as a dark layer (Fig. 6). Surfaces of the oxidized samples after $100 \mathrm{~h}$ at $60^{\circ} \mathrm{C}, 95^{\circ} \mathrm{C}$, and $130^{\circ} \mathrm{C}$ are shown in Fig. 7. Several interesting features can be seen on the surface of the oxidized specimens. First, Sn grain relief is visible in the $\mathrm{Sn}$ dendrite regions surrounding the oxidized $\mathrm{RE}$ intermetallics. This feature seems more prominent at lower temperatures, and is present in all three alloys. Secondly, Sn whiskering takes place on the surfaces of the alloys during oxidation. Hillock-type whiskers are present on the specimen surfaces of $\mathrm{Sn}-3.9 \mathrm{Ag}-0.7 \mathrm{Cu}-2 \mathrm{La}$ and $\mathrm{Sn}-3.9 \mathrm{Ag}-0.7 \mathrm{Cu}-2 \mathrm{Y}$ at all temperatures. A smaller amount of whiskering 

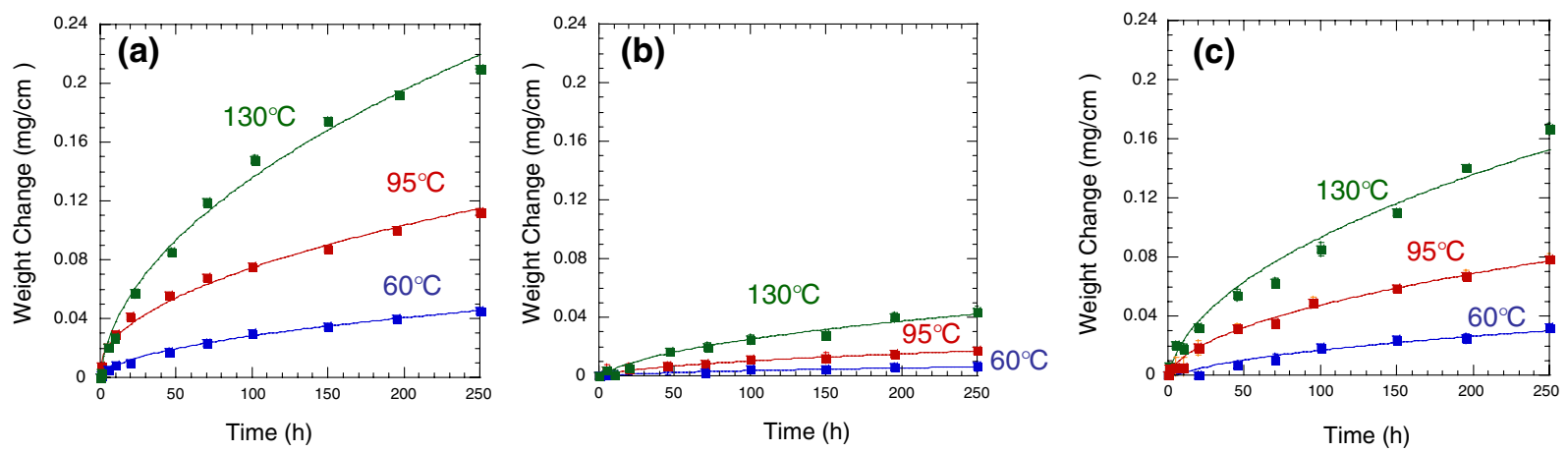

Fig. 4. Normalized mass increase versus time curves for (a) Sn-3.9Ag-0.7Cu-2La, (b) Sn-3.9Ag-0.7Cu-2Ce, and (c) Sn-3.9Ag-0.7Cu-2Y at $60^{\circ} \mathrm{C}, 95^{\circ} \mathrm{C}$, and $130^{\circ} \mathrm{C}$.
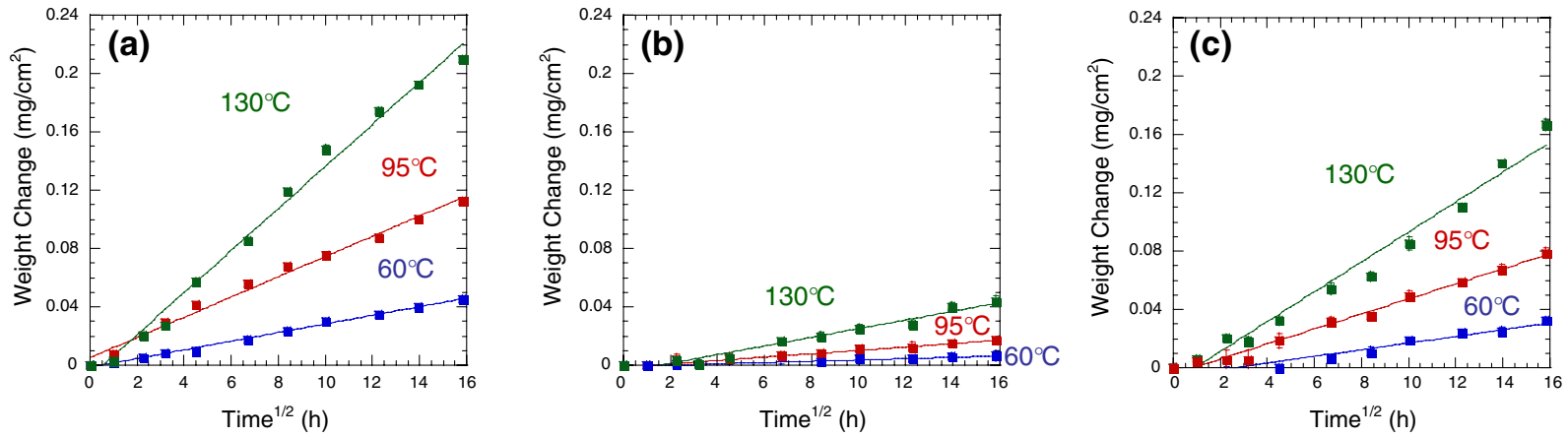

Fig. 5. Normalized mass increase versus time ${ }^{1 / 2}$ curves for (a) Sn-3.9Ag-0.7Cu-2La, (b) Sn-3.9Ag-0.7Cu-2Ce, and (c) Sn-3.9Ag-0.7Cu-2Y at $60^{\circ} \mathrm{C}, 95^{\circ} \mathrm{C}$, and $130^{\circ} \mathrm{C}$.

Table II. Parabolic Rate Constants for

Sn-3.9Ag-0.7Cu-2La, Sn-3.9Ag-0.7Cu-2Ce, and $\mathrm{Sn}-3.9 \mathrm{Ag}-0.7 \mathrm{Cu}-2 \mathrm{Y}$ at $60^{\circ} \mathrm{C}, 95^{\circ} \mathrm{C}$, and $130^{\circ} \mathrm{C}$

\begin{tabular}{|c|c|c|c|}
\hline \multirow[b]{2}{*}{ Material } & \multicolumn{3}{|c|}{$\begin{array}{c}\text { Oxidation Rate } \times 10^{-4}, \\
k_{p}\left(\mathrm{mg} / \mathrm{cm}^{2} \mathrm{~h}^{1 / 2}\right)\end{array}$} \\
\hline & $60^{\circ} \mathrm{C}$ & $95^{\circ} \mathrm{C}$ & $130^{\circ} \mathrm{C}$ \\
\hline Sn-3.9Ag-0.7Cu-2La & $29.6 \pm 0.6$ & $82.0 \pm 2.7$ & $141 \pm 9.3$ \\
\hline $\mathrm{Sn}-3.9 \mathrm{Ag}-0.7 \mathrm{Cu}-2 \mathrm{Ce}$ & $4.5 \pm 0.1$ & $11.8 \pm 1.7$ & $29.7 \pm 1.8$ \\
\hline $\mathrm{Sn}-3.9 \mathrm{Ag}-0.7 \mathrm{Cu}-2 \mathrm{Y}$ & $22.8 \pm 1.9$ & $93.0 \pm 2.9$ & $103 \pm 5.5$ \\
\hline
\end{tabular}

\section{Table III. Activation Energies for Oxidation} of Sn-3.9Ag-0.7Cu-2La, Sn-3.9Ag-0.7Cu-2Ce, and $\mathrm{Sn}-3.9 \mathrm{Ag}-0.7 \mathrm{Cu}-2 \mathrm{Y}$ in the Temperature Range $60^{\circ} \mathrm{C}$ to $130^{\circ} \mathrm{C}$

\begin{tabular}{lc}
\hline Material & Activation Energy (kJ/mol) \\
Sn-3.9Ag-0.7Cu-2La & 25.1 \\
Sn-3.9Ag-0.7Cu-2Ce & 30.0 \\
Sn-3.9Ag-0.7Cu-2Y & 24.0 \\
\hline
\end{tabular}

takes place on Sn-3.9Ag-0.7Cu-2Ce at $130^{\circ} \mathrm{C}$, but virtually no whiskering is present at $60^{\circ} \mathrm{C}$ and $95^{\circ} \mathrm{C}$. Some needle-like whiskers also are seen on $\mathrm{Sn}-3.9 \mathrm{Ag}-0.7 \mathrm{Cu}-2 \mathrm{La}$ and $\mathrm{Sn}-3.9 \mathrm{Ag}-0.7 \mathrm{Cu}-2 \mathrm{Y}$. It is

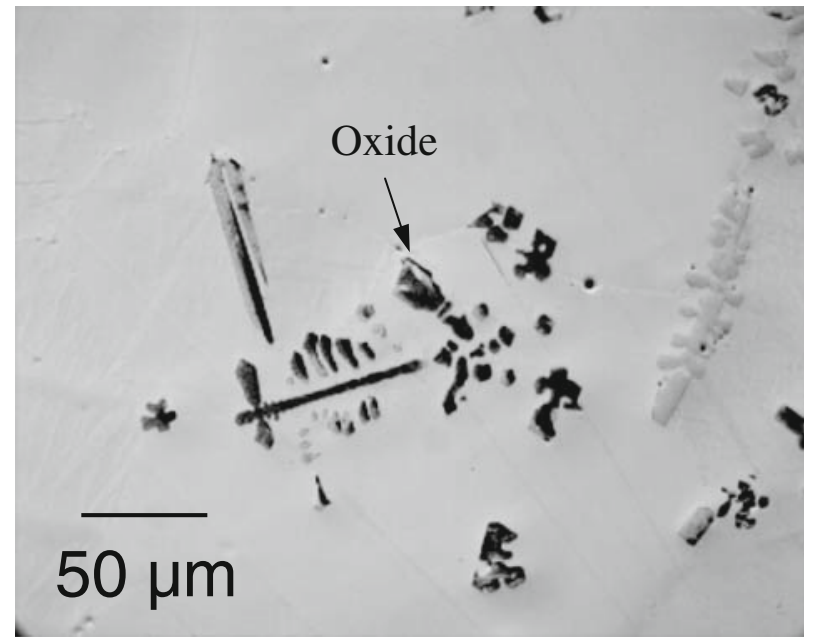

Fig. 6. Optical image of oxide formation on $\mathrm{LaSn}_{3}$ after $10 \mathrm{~min}$ of exposure at $25^{\circ} \mathrm{C}$.

clear from the micrographs that Sn-3.9Ag-0.7Cu2Ce has a far lower propensity for whisker formation compared with $\mathrm{Sn}-3.9 \mathrm{Ag}-0.7 \mathrm{Cu}-2 \mathrm{La}$ and $\mathrm{Sn}-$ $3.9 \mathrm{Ag}-0.7 \mathrm{Cu}-2 \mathrm{Y}$. This observation suggests that there is a positive correlation between Sn whisker growth and $\mathrm{RE}$ oxidation.

As the oxidation temperature is increased, Sn-3.9 Ag-0.7Cu-2La and Sn-3.9Ag-0.7Cu-2Y undergo more 

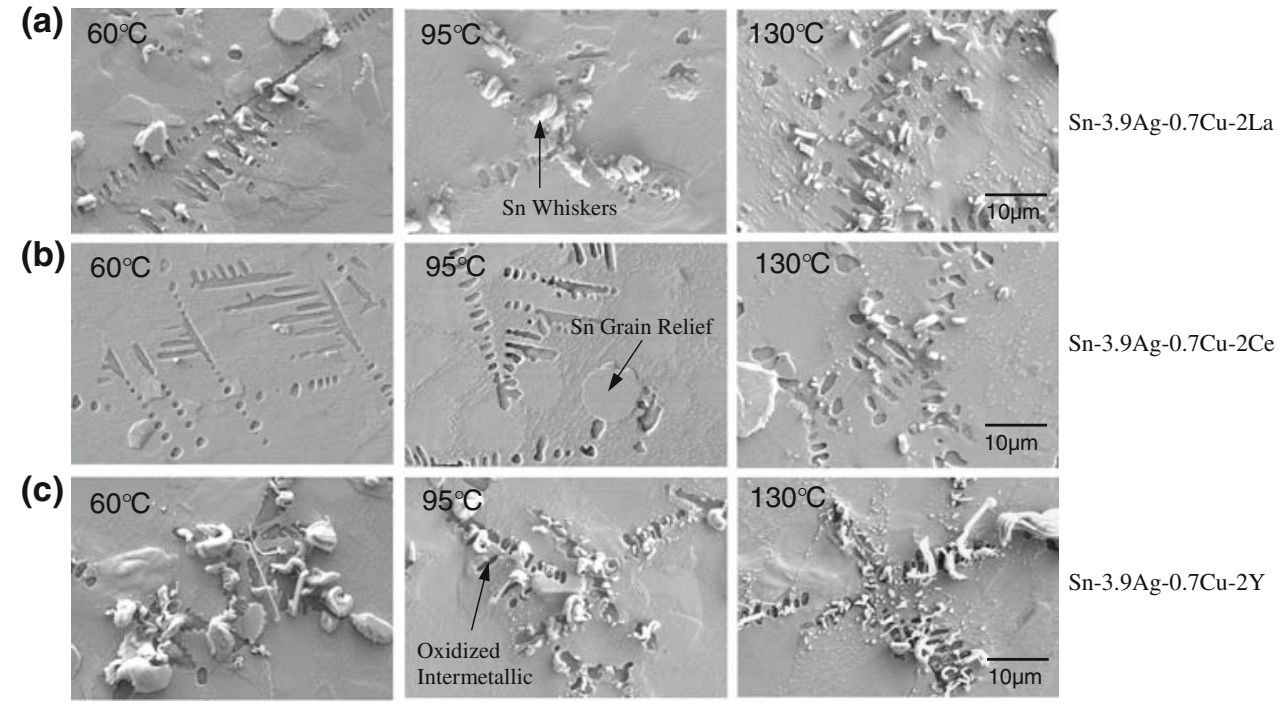

Fig. 7. SEM images of surface oxidation of (a) Sn-3.9Ag-0.7Cu-2La, (b) Sn-3.9Ag-0.7Cu-2Ce, and (c) Sn-3.9Ag-0.7Cu-2Y at $60^{\circ} \mathrm{C}, 95^{\circ} \mathrm{C}$, and $130^{\circ} \mathrm{C}$ after $100 \mathrm{~h}$. Note the $\mathrm{Sn}$ grain relief surrounding RES $\mathrm{n}_{3}$ particles and the formation of $\mathrm{Sn}$ whiskers.

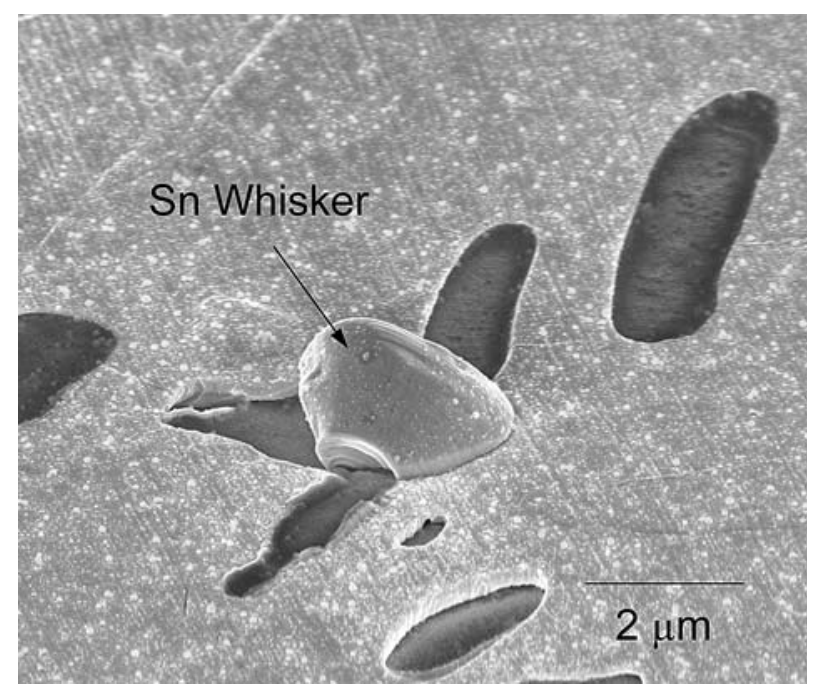

Fig. 8. High-magnification SEM image of hillock-type whisker grown on Sn-3.9Ag-0.7Cu-2La at $60^{\circ} \mathrm{C}$.

severe whisker growth. At low temperatures, the hillock-type whiskers seem to grow close to the $\mathrm{Sn}$ matrix/RE intermetallic interface. Figure 8 shows a higher magnification of such a whisker on Sn-3.9Ag$0.7 \mathrm{Cu}-2 \mathrm{La}$ near the boundary between a $\mathrm{LaSn}_{3}$ particle and the Sn matrix. As the oxidation temperature is increased, hillock-type whisker growth adjacent to the RE intermetallics is accompanied by the growth of whiskers in the eutectic region of the alloys surrounding the $\mathrm{RE}$ particles. This is most apparent at $130^{\circ} \mathrm{C}$. Cracking is also present on the surfaces of the oxide phases for $\mathrm{Sn}-3.9 \mathrm{Ag}-0.7 \mathrm{Cu}-2 \mathrm{La}$ and $\mathrm{Sn}-3.9 \mathrm{Ag}-$ $0.7 \mathrm{Cu}-2 \mathrm{Y}$.

Backscattered-electron SEM images of polished cross-sections of Sn-3.9Ag-0.7Cu-2La, Sn-3.9Ag-0.7
Cu-2Ce, and Sn-3.9Ag-0.7Cu-2Y oxidized for $100 \mathrm{~h}$ at $95^{\circ} \mathrm{C}$ are shown in Fig. 9. The dotted line in the figure denotes the depth of oxide penetration, i.e., $\mathrm{RE}$ intermetallic particles below the line have not oxidized. It appears that oxide infiltration is dominated by the diffusion of oxygen into the RE-containing phases, and not through the Sn matrix. The dark oxides also appear to be somewhat porous, and some cracking is observed in these regions in areas under the sample surface. The oxide reaction front in both the La- and Y-containing solders has advanced a substantial amount into the bulk of the solder, while for the Ce-containing solder, the oxide does not penetrate past the surface. Only $\mathrm{RE}$ intermetallics in direct contact with the specimen surface oxidized, indicating that little oxygen diffusion through the Sn matrix was taking place. Penetration depths after $100 \mathrm{~h}$ of oxidation were measured and are shown in Table IV. As with the oxidation rates, $\mathrm{Sn}-3.9 \mathrm{Ag}-0.7 \mathrm{Cu}-2 \mathrm{Ce}$ had an order of magnitude smaller oxide penetration compared with Sn-3.9Ag-0.7Cu-2La and Sn-3.9Ag-0.7Cu-2Y.

Concentrations of $\mathrm{Sn}, \mathrm{RE}, \mathrm{O}, \mathrm{Ag}$, and $\mathrm{Cu}$ were measured on cross-sections of the oxidized specimens by means of EDS. A typical concentration profile for a partially oxidized $\mathrm{LaSn}_{3}$ particle is shown in Fig. 10. The concentration of $\mathrm{Sn}$ in the oxide layer is very low. It increases at the alloy/ $\mathrm{LaSn}_{3}$ interface to the concentration level expected by the nominal stoichiometry of this phase. The oxide layer is rich in both La and O. At a short distance from the oxide-intermetallic interface no Sn enrichment was observed. Since the EDS data showed that $\mathrm{Sn}$ was present in small amounts within the oxide layer only, and that there was no Sn enrichment in the intermetallic phase, the Sn should have migrated to the adjacent Sn matrix. More work is required to support this hypothesis. 

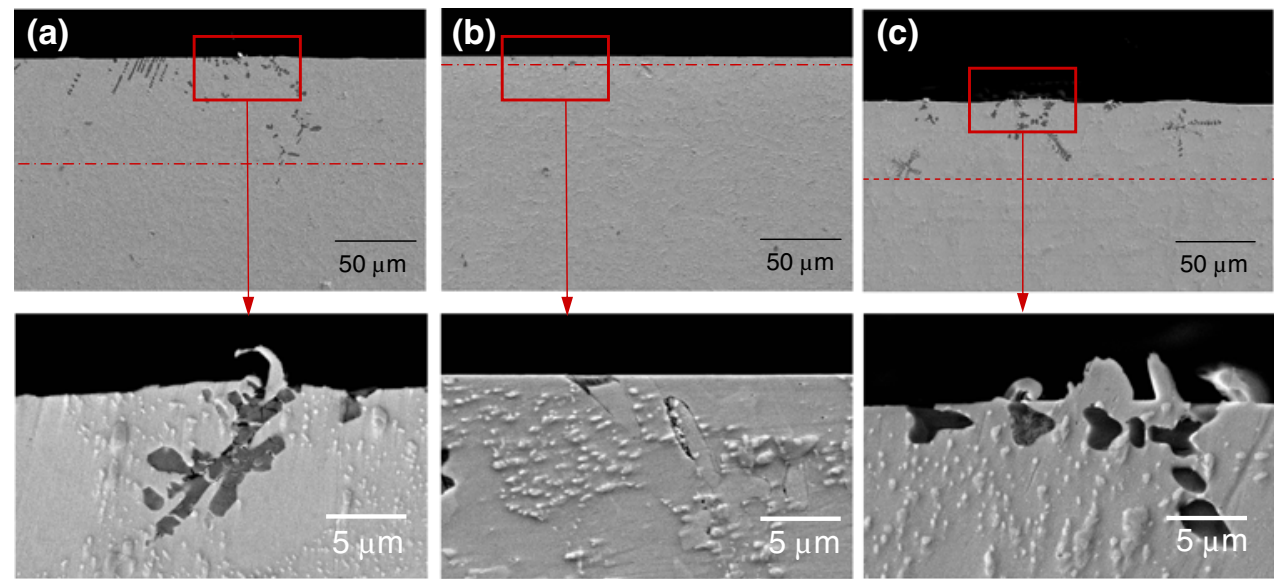

Fig. 9. Backscattered-electron SEM images of polished cross-sections of Sn-3.9Ag-0.7Cu-2La, Sn-3.9Ag-0.7Cu-2Ce, and Sn-3.9Ag-0.7Cu-2Y oxidized for $100 \mathrm{~h}$ at $95^{\circ} \mathrm{C}$. Oxidized RE intermetallics appear dark. RE intermetallic particles below the dashed lines have not oxidized.

Table IV. Oxide Penetration Depths after $100 \mathrm{~h}$ of Oxidation

\begin{tabular}{|c|c|c|c|}
\hline \multirow[b]{2}{*}{ Material } & \multicolumn{3}{|c|}{$\begin{array}{c}\text { Oxidation Penetration } \\
\text { at } 100 \mathrm{~h}(\mu \mathrm{m})\end{array}$} \\
\hline & $60^{\circ} \mathrm{C}$ & $95^{\circ} \mathrm{C}$ & $130^{\circ} \mathrm{C}$ \\
\hline Sn-3.9Ag-0.7Cu-2La & $26 \pm 5$ & $47 \pm 16$ & $97 \pm 19$ \\
\hline $\mathrm{Sn}-3.9 \mathrm{Ag}-0.7 \mathrm{Cu}-2 \mathrm{Ce}$ & $2 \pm 1$ & $5 \pm 3$ & $27 \pm 9$ \\
\hline Sn-3.9Ag-0.7Cu-2Y & $23 \pm 8$ & $46 \pm 12$ & $75 \pm 34$ \\
\hline
\end{tabular}

From Fig. 10 it is apparent that the RE element in the $\mathrm{RESn}_{3}$ intermetallics is oxidizing, resulting in a RE-rich oxide. Selective oxidation wherein a less noble constituent in an alloy is preferentially oxidized is a common phenomenon, particularly when the oxides of each alloy constituent do not react with one another and are mutually insoluble. ${ }^{34}$ According to the theory for selective oxidation by Wagner $33,35,36$ the less noble metal is selectively oxidized, forming an outer oxide layer, and the more noble metal avoids oxidation and diffuses from the oxide front into the bulk of the alloy, causing an
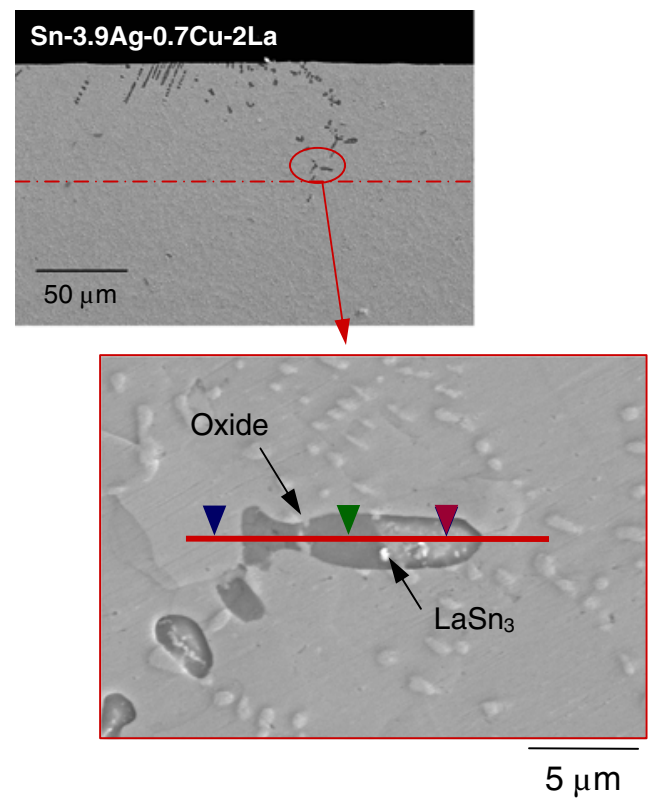
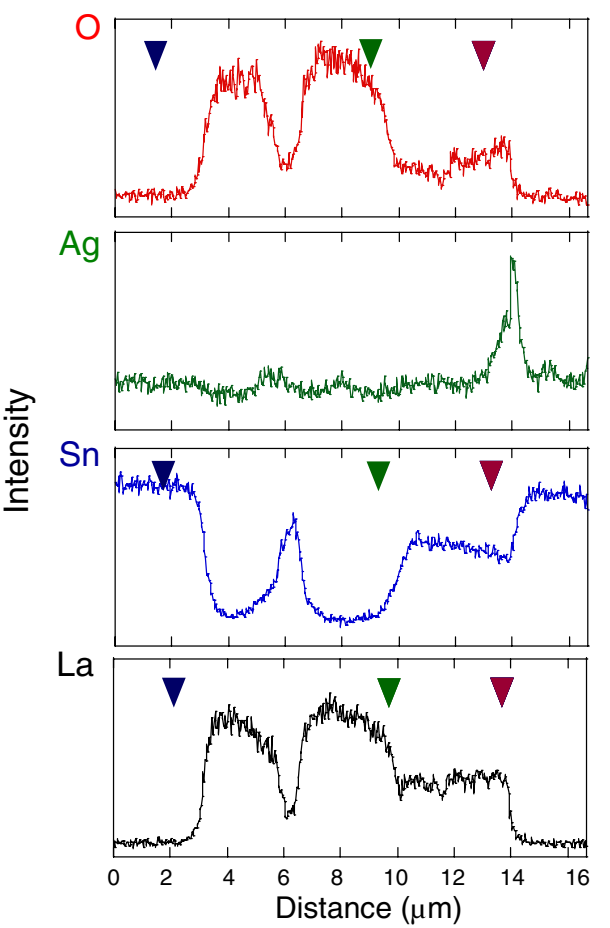

Fig. 10. SEM micrograph and EDX data for cross-sectioned partially oxidized $\mathrm{LaSn}_{3}$ particle in Sn-3.9Ag-0.7Cu-2La after $100 \mathrm{~h}$, oxidized at $95^{\circ} \mathrm{C}$. 
Table V. Gibbs Free Energies of Formation for RE and Sn Oxides ${ }^{37}$

\begin{tabular}{lc}
\hline Oxide Compound & $\begin{array}{c}\text { Gibbs Free Energy } \\
\text { of Formation (kJ/mol) }\end{array}$ \\
\cline { 2 - 2 } $\mathrm{SnO}$ & -251.9 \\
$\mathrm{SnO}_{2}$ & -515.8 \\
$\mathrm{La}_{2} \mathrm{O}_{3}$ & -1705.8 \\
$\mathrm{CeO}_{2}$ & -1024.7 \\
$\mathrm{Y}_{2} \mathrm{O}_{3}$ & -1816.7 \\
\hline
\end{tabular}

enrichment of that element in the alloy. Gibbs free energies of formation ${ }^{37}$ for the RE-O phases of interest and Sn-O phases are shown in Table V. The free energies of formation indicate that the $\mathrm{RE}$ constituents are in fact the less noble elements in $\mathrm{RESn}_{3}$ intermetallics.

The selective oxidation of $\mathrm{RE}$ in $\mathrm{RESn}_{3}$ may take place by the following net reactions:

$$
\begin{gathered}
2 \mathrm{LaSn}_{3}+\frac{3}{2} \mathrm{O}_{2} \rightarrow \mathrm{La}_{2} \mathrm{O}_{3}+6 \mathrm{Sn} \\
\mathrm{CeSn}_{3}+\mathrm{O}_{2} \rightarrow \mathrm{CeO}_{2}+3 \mathrm{Sn} \\
2 \mathrm{YSn}_{3}+\frac{3}{2} \mathrm{O}_{2} \rightarrow \mathrm{Y}_{2} \mathrm{O}_{3}+6 \mathrm{Sn}
\end{gathered}
$$

Jiang and $\mathrm{Xian}^{23}$ proposed that the $\mathrm{ReSn}_{3}$ may first decompose to elemental RE and Sn before oxidation. This seems unlikely as the $\mathrm{RESn}_{3}$ phases are thermodynamically stable at low temperatures. Without externally applied forces or constraints, the oxidation of $\mathrm{LaSn}_{3}$ and $\mathrm{CeSn}_{3}$ according to the above equations would result in volume increases of about $16.2 \%$ and $12.3 \%$, respectively. However, the intermetallic phases are constrained from expansion during oxidation due to the surrounding Sn matrix. Due to the inevitable reaction of the $\mathrm{RE}$ with $\mathrm{O}$, the $\mathrm{Sn}$ in the oxidized zone is under a state of compression. The stresses imposed on the Sn result in its outward migration to the surrounding $\mathrm{Sn}$ matrix, instead of migration into the intermetallic. Once in the Sn matrix, we believe that the Sn atoms migrate along dislocations and/or grain boundaries in the direction of the compressive stress gradient, to the stress-free surface of the specimen, causing whisker growth. It is well recognized that compressive stresses are a necessary condition for $\mathrm{Sn}$ whisker formation on thin Sn platings. ${ }^{38-41}$ It is believed that $\mathrm{Sn}$ atoms diffuse from regions of high compressive stresses (generally caused by the growth of a $\mathrm{Cu}_{6} \mathrm{Sn}_{5}$ intermetallic layer) to the stress-free film surface by diffusion along columnar Sn grain boundaries. Observations seen in the current study agree well with those reported in the literature.
As noted previously, at higher temperatures hillock-type whiskers are accompanied by the growth of smaller whiskers in the eutectic region of the solder. One possible explanation for this is the increasing contribution of lattice diffusion of Sn at higher temperatures. At lower temperatures, Sn diffusion along grain boundaries in close proximity to the oxidized particle is likely energetically favorable, resulting in hillock-type whiskers close to the intermetallic/Sn matrix interface. As the temperature is increased, lattice diffusion plays a stronger role and the $\mathrm{Sn}$ atoms are able to travel much farther to the surrounding eutectic region. In fact, it has been observed that lattice diffusion in Sn alloys under stress becomes significant at temperatures $>100^{\circ} \mathrm{C}$, which correlates well with our observations. ${ }^{42,43}$

XRD was conducted on the oxidized specimens in order to determine the oxide phases that were formed. According to the respective RE-O phase diagrams, ${ }^{32} \mathrm{La}_{2} \mathrm{O}_{3}, \mathrm{CeO}_{2}$, and $\mathrm{Y}_{2} \mathrm{O}_{3}$ are expected to exist at ambient temperatures and pressure. The XRD patterns for all three alloys showed no oxide peaks. The RE-Sn intermetallic phases were no longer detectable. $\mathrm{SnO}_{2}$ and $\mathrm{SnO}$ were also not detected. Chuang ${ }^{19}$ observed that $\mathrm{CeSn}_{3}$ oxidizes to form crystalline $\mathrm{CeO}_{2}$. It is possible, however, that at low temperatures and under certain oxidizing conditions the oxide phases that form on intermetallics can be "weakly crystalline" or possibly amorphous. ${ }^{44,45}$ The phases that form during oxidation of these materials requires further study.

As mentioned previously, parabolic oxidation dependence indicates that diffusion of the reacting species is rate controlling. Diffusion of oxygen through the oxide layer, or the diffusion of the $\mathrm{RE}$ element in the RE intermetallic to the oxide/metal interface, could be rate-determining processes. Generally, when the diffusion of the metal ion to the oxide/alloy is rate controlling, a depleted region of the reacting metal will develop in the alloy at the alloy/oxide interface. ${ }^{34}$ As this layer grows, diffusion of the metal ion becomes more sluggish, and the oxidation rate decreases due to a decreased availability of metal ions for reaction. As shown in Fig. 10, however, no enrichment layer was present in these alloys. Therefore, diffusion through the oxide layer is likely the rate-controlling process in these alloys.

Initial oxidation takes place rather quickly and a dark layer of oxide can be seen optically within several minutes. As with other metal systems, growth of the oxide layer begins with the adsorption of oxygen onto the intermetallic surface (monolayer). The nucleation of oxide islands a few atomic layers thick follows. Once these oxide nuclei coalesce to form a continuous layer, further oxidation proceeds by a diffusion mechanism. ${ }^{34}$ Since the oxide was observed to grow inward from the specimen surface, oxygen must diffuse through the oxide layer to the intermetallic-oxide interface. When oxygen reaches the interface, fresh oxide is formed. 
Oxygen can diffuse through the oxide in several ways including ionic diffusion and molecular diffusion through defects in the oxide. Molecular oxygen can penetrate through the cracks and pores in the oxide layer to-or close to-the oxide/intermetallic interface. It could then react with the $\mathrm{RE}$ ions to form an oxide phase. This type of transport takes place in nonprotective oxide layers and would not obey parabolic kinetics. ${ }^{46}$ If the oxide layer was initially protective, and cracking occurred during further oxidation, paralinear oxidation kinetics would be expected. Here, the rate is initially parabolic, but a transition to linear behavior is observed once significant cracking or porosity is present. ${ }^{46}$ Although porosity and cracking were observed in the oxide phases, parabolic kinetics dominated. Thus, the diffusion of oxygen is likely governed by the diffusion of oxygen ions through the oxide layer via a vacancy mechanism. The vacancy mechanism process consists of the exchange of oxygen ions and oxygen vacancies. Both electrons and vacancies travel from the intermetallic-oxide interface to the outer surface of the oxide layer. A reaction takes place between two electrons, a vacancy, and an oxygen molecule. This produces an oxygen ion at the oxide surface, which is then able to move through the oxide via a vacancy process. It is known that both $\mathrm{La}_{2} \mathrm{O}_{3}$ and $\mathrm{Y}_{2} \mathrm{O}_{3}$ can be oxygen deficient, described more accurately as $\mathrm{La}_{2} \mathrm{O}_{3-x}$ and $\mathrm{Y}_{2} \mathrm{O}_{3-x}$. Deficiency in oxygen results in a high concentration of oxygen vacancies, making oxygen diffusion through the structures easier. Thus, oxygen diffusion rates through the oxides can be high. ${ }^{47}$ Any differences in oxide structure (and related nonstoichiometry) may result in different oxygen diffusion rates through the various oxides, and lead to the differences in observed oxidation rates between alloys.

Hillock-type Sn whiskers developed on Sn-3.9Ag$0.7 \mathrm{Cu}-2 \mathrm{La}$ alloys were cross-sectioned and imaged with a FIB using the ion beam (Fig. 11). The phenomenon of Sn whiskering is treated in more detail elsewhere. ${ }^{48}$ The Sn whiskers have a different orientation than the Sn grains in the matrix in direct contact with the whisker. Due to the ion channeling effect, grains of the same material with different orientations will have different contrast in ion beam images. In addition, the base of Sn whisker grains have oblique angle grain boundaries with respect to the Sn matrix grains and the free surface. These findings are in good agreement with reported observations of Sn whisker growth on thin Sn films. ${ }^{38-41}$ In these studies it has been shown that whisker grains resulting from the recrystallization of thin Sn platings have boundaries neither parallel nor perpendicular to the columnar Sn grains or the plating surface. These recrystallized grains also have a different orientation than the surrounding as-plated microstructure. These observations suggest that the conditions for whisker growth in these alloys may be similar to those in thin films.

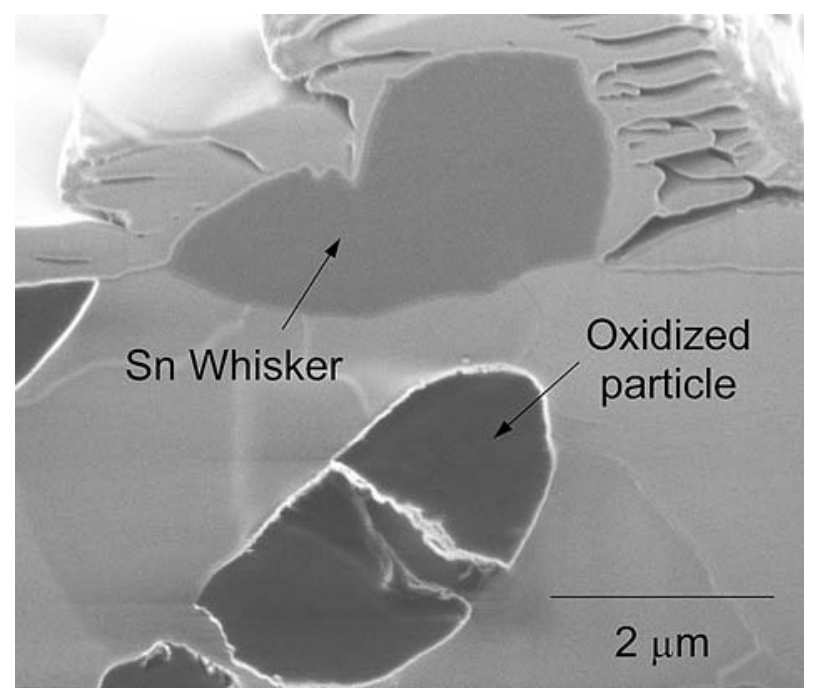

Fig. 11. FIB cross-section of Sn whisker formed on Sn-3.9Ag-0.7Cu2La.

The results of Chuang and co-authors ${ }^{19-22}$ on the whiskering behavior of RE-containing solders contrast slightly with the results of this study. For example, in a study conducted on Sn-6.6RE $(\mathrm{RE}=\mathrm{Ce}, \mathrm{La}$, and $\mathrm{Lu})$, they observed that the La-containing alloy whiskered less than alloys containing $\mathrm{Ce}$ and $\mathrm{Lu}^{22}$ However, the size of the $\mathrm{CeSn}_{3}$ and $\mathrm{Lu}_{4} \mathrm{Sn}_{5}$ phases that formed in the alloys were approximately five times larger than the $\mathrm{LaSn}_{3}$ intermetallics. Although they state that the area fraction of the particles was similar, it is clear that the stress state developed during oxidation of these materials significantly influences the propensity for whisker formation. The size, morphology, and distribution of the intermetallic phases will ultimately affect the stress state and can lead to differences in whiskering behavior. Kinetic data showed large differences in oxidation rates between the materials; however, cross-sections of their specimens did not reveal significant differences in oxide thickness between the alloys. It is unclear whether the kinetic data accounted for differences in surface area between the samples. Nonetheless, this strengthens the argument that the size and distribution of the particles will affect both the oxidation and whiskering behavior. In a similar study, ${ }^{21}$ they observed the prevalence of hillock-type whiskers on $\mathrm{Lu}_{4} \mathrm{Sn}_{5}$ phases in a $\mathrm{Sn}-6.6 \mathrm{Lu}$ alloy at high temperatures, and thread-like whiskers at low temperatures, emanating from the center of the particles. Many of the discrepancies are likely due to differences in the initial microstructures of the solders, in particular the size, morphology, and distribution of the RE intermetallic phases. Chuang and $\mathrm{Yen}^{20}$ observed significant whisker formation from the center of the oxidized intermetallics in a reflowed Sn-3Ag-0.5Cu-0.5Ce alloy, where the majority of whisker formation in this study occurred at the Sn matrix/intermetallic interface. However, 
It should be noted that, although the composition of the alloy used in their study is similar to that used in this work, the size and morphology of their $\mathrm{CeSn}_{3}$ intermetallics were very different. The $\mathrm{CeSn}_{3}$ phases again were quite large $(\sim 40 \mu \mathrm{m})$ and discrete. Whisker formation in the eutectic region of the alloy was not observed, even after 21 days at $100^{\circ} \mathrm{C}$. This result could be directly related to the size and morphology of the intermetallic particles, and thus the diffusion pathway for Sn atoms may differ. More detailed studies need to be carried out in order to examine the relationship between intermetallic size, morphology, and oxidation/whiskering behavior.

\section{CONCLUSIONS}

The relationship between composition, microstructure, and oxidation behavior of a novel class of $\mathrm{Pb}$-free solders containing rare-earth elements was investigated. Based on the experimental results, the following conclusions can be drawn: (1) The as-processed microstructure of $\mathrm{Sn}-3.9 \mathrm{Ag}-0.7 \mathrm{Cu}-2 \mathrm{La}$, $\mathrm{Sn}-3.9 \mathrm{Ag}-0.7 \mathrm{Cu}-2 \mathrm{Ce}$, and $\mathrm{Sn}-3.9 \mathrm{Ag}-0.7 \mathrm{Cu}-2 \mathrm{Y}$ contained RE intermetallics of the type $\mathrm{RESn}_{3}$ that are dendritic in nature, and exist in the eutectic region of the solder microstructure and along the Sn dendrite boundaries. The RE intermetallic phases between the alloys had similar volume fraction, morphology, size, and spacing. (2) The oxidation behavior of these alloys follows a parabolic rate law. $\mathrm{Sn}-3.9 \mathrm{Ag}-0.7 \mathrm{Cu}-2 \mathrm{Ce}$ exhibited the best oxidation resistance, with an order of magnitude smaller oxidation rate for all temperatures studied. This result is promising for the incorporation of $\mathrm{Ce}$ into $\mathrm{Pb}$-free solders. (3) Selective oxidation of the $\mathrm{RESn}_{3}$ phases occurs, leading to a RE-rich oxide. Oxygen diffuses through the oxide film to the metal/oxide interface, most likely by an oxygen vacancy mechanism. (4) Oxidation of the RE intermetallics leads to compressive stresses that ultimately cause the formation of Sn whiskers on the surface of the material. A more detailed study of the factors influencing the whisker formation, in addition to the mechanism for their formation, needs to be conducted.

\section{ACKNOWLEDGEMENTS}

The authors acknowledge financial support for this research from the Semiconductor Research Corporation (SRC) under Contract \# 2005-KJ-1286 (Dr. Scott List, Program Manager, and Drs. M. Renavikar, P. Brofman, and K. Zeng, industrial liaisons). The authors also thank David Wright from the Center for Solid State Science, Arizona State University for his assistance with sealing the ampoules, and Dr. Jason Williams for useful discussions on the oxidation behavior of rare-earth elements.

\section{REFERENCES}

1. A. Ramirez, H. Mavoori, and S. Jin, Appl. Phys. Lett. 80, 398 (2002).
2. C.M.L. Wu, D.Q. Yu, C.M.T. Law, and L.J. Wang, Mater. Res. 17, 3146 (2002).

3. Z. Xia, Z. Chen, Y. Shi, N. Mu, and N. Sun, J. Electron. Mater. 31, 564 (2002). doi:10.1007/s11664-002-0126-3.

4. Z.G. Chen, Y.W. Shi, Z.D. Xia, and Y.F. Yan, J. Electron. Mater. 31, 1122 (2002).

5. L. Wang, D.Q. Wu, J. Zhao, and M.L. Huang, Mater. Lett. 56, 1039 (2002). doi:10.1016/S0167-577X(02)00672-9.

6. C.M.L. Wu, C.M.T. Law, D.Q. Yu, and L. Wang, J. Electron. Mater. 32, 63 (2003).

7. Z.G. Chen, Y.W. Shi, Z.D. Xia, and Y.F. Yan, J. Electron. Mater. 32, 235 (2003).

8. M. Dittes and H. Walter, Solder. Surf. Mount. Technol. 15, 50 (2003).

9. D.Q. Yu, J. Zhao, and L. Wang, J. Alloy Compd. 376, 170 (2004). doi:10.1016/j.jallcom.2004.01.012.

10. C.M.T. Law, C.M.L. Wu, D.Q. Yu, M. Li, and D.Z. Chi, IEEE Trans. Adv. Packag. 28, 252 (2005). doi:10.1109/ TADVP.2005.846939.

11. M.A. Dudek, R.S. Sidhu, N. Chawla, and M. Renavikar, J. Electron. Mater. 35, 2088 (2006).

12. M.A. Dudek, R.S. Sidhu, and N. Chawla, JOM 58, 57 (2006).

13. D.Q. Yu, C.M.L. Wu, and Y.W. Wong, J. Mater. Sci.: Mater. Electron. 18, 1057 (2007). doi:10.1007/s10854-006-9114-3.

14. C.M.L. Wu and Y.W. Wong, J. Mater. Sci.: Mater. Electron. 18, 77 (2007). doi:10.1007/s10854-006-9022-6.

15. H. Hao, J. Tian, Y.W. Shi, Y.P. Lei, and Z.D. Xia, J. Electron. Mater. 36, 766 (2007).

16. Y. Shi, J. Tian, H. Hao, Z. Xia, Y. Lei, and F. Guo, J. Alloy Compd. 453, 180 (2008). doi:10.1016/j.jallcom.2006.11.165.

17. M. Pei and J. Qu, J. Electron. Mater. 37, 331 (2008).

18. M.A. Dudek and N. Chawla. J. Electron. Mater. (2008), in preparation.

19. T.H. Chuang, Scripta Mater. 55, 983 (2006). doi:10.1016/ j.scriptamat.2006.08.024.

20. T.H. Chuang and S.F. Yen, J. Electron. Mater. 35, 1621 (2006).

21. T.H. Chuang, H.J. Lin, and C.C. Chi, Scripta Mater. 56, 45 (2007). doi:10.1016/j.scriptamat.2006.08.061.

22. T.N. Chuang, C.C. Chi, and H.J. Lin, Metall. Mater. Trans. A 39A, 604 (2008). doi:10.1007/s11661-007-9426-9.

23. B. Jiang and A.P. Xian, Phil. Mag. Lett. 87, 657 (2007).

24. Y. Niu, G.Y. Fu, W.T. Wu, and F. Gesmundo, High Temp. Mater. Process. 18, 159 (1999).

25. Y. Niu, F. Gesmundo, M. Al-Omary, and J. Song, J. Alloy Compd. 317-318, 573 (2001). doi:10.1016/S0925-8388(00) 01390-6

26. Y. Niu, Y.S. Li, F. Gesmundo, and F. Viani, Intermetallics 8, 293 (2000). doi:10.1016/S0966-9795(99)00106-5.

27. I. Anzel, Z. Metallkd. 94, 993 (2003).

28. X. Deng, N. Chawla, F. Tang, I.E. Anderson, and B. Glesson, Materials Science and Technology 2005 (Warrendale, PA: The Minerals, Metals, and Materials Society, 2005).

29. M.A. Dudek and N. Chawla, Mater. Character. 59, 1364 (2008).

30. A. Palenzona and P. Manfrinetti, J. Alloy Compd. 201, 43 (1993). doi:10.1016/0925-8388(93)90859-L.

31. R.V. Skolozdra, L.G. Akselrud, V.K. Pecharskii, and O.E. Koretskaya, Dokl. Akad. Nauk Ukr. RSR Ser. B 12, 51 (1986).

32. H. Okamoto, ed., Desk Handbook: Phase Diagrams for Binary Alloys (Materials Park, OH: ASM, 2000).

33. C. Wagner, J. Electrochem. Soc. 99, 369 (1952). doi:10.1149/ 1.2779605 .

34. K. Hauffe, Oxidation of Metals (New York, NY: Plenum Park, 1965).

35. C. Wagner, J. Electrochem. Soc. 103, 571 (1956).

36. C. Wagner, Z. Elecktrochem. 63, 772 (1959).

37. J.A. Dean, Lange's Handbook of Chemistry, 15th ed. (New York, NY: McGraw-Hill, 1999).

38. G.T. Gaylon and L. Palmer, IEEE Trans. Electron. Packag. Manuf. 28, 17 (2005).

39. K.N. Tu, C. Chen, and A.T. Wu, J. Mater. Sci. Mater. Electron. 18, 269 (2007). doi:10.1007/s10854-006-9029-z. 
40. G.T.T. Sheng, C.F. Hu, W.J. Choi, K.N. Tu, Y.Y. Bong, and L. Nguyen, J. Appl. Phys. 92, 64 (2002). doi:10.1063/ 1.1481202.

41. J. Smetana, IEEE Trans. Electron. Packag. Manuf. 30, 11 (2007).

42. M. Kerr and N. Chawla, Acta Mater. 52, 4527 (2004). doi:10.1016/j.actamat.2004.06.010.

43. R.S. Sidhu, X. Deng, and N. Chawla, Metall. Mater. Trans. A 39, 349 (2008). doi:10.1007/s11661-007-9412-2.
44. M. Paljević and Z. Ban, J. Nucl. Mater. 95, 253 (1980). doi:10.1016/0022-3115(80)90366-9.

45. M. Paljević, J. Alloy Compd. 191, 27 (1993). doi:10.1016/ 0925-8388(93)90266-P.

46. P. Koftad, High Temperature Corrosion (New York, NY: Elsevier Applied Science, 1988).

47. M. Zinkevich, Prog. Mater. Sci. 52, 597 (2007).

48. M.A. Dudek and N. Chawla (2008), unpublished work. 